\title{
Human Resources Development and its Impact on The Performance of Individuals in Universities
}

\author{
Mashael Shaye M Alghofaily \\ College of Business Administration \\ University of Business \& Technology \\ Kingdom of Saudi Arabia
}

\begin{abstract}
The study aimed to emphasize the importance of human resources and the need for strategic direction in their development in universities, as one of the main pillars of achieving excellence, and to arrange human resources development strategies in universities, Emphasizing the need for the university to use modern management methods in the development of its human resources-engineering the performance of the university and measuring the quality of the human resources performance, revealing the reality of human resources development in universities and the strategies adopted in them, and identifying strategies that can raise the level of performance of the university. There is a relationship of statistical significance at a moral level 0.05. There is a relationship of statistical significance at a moral level 0.05. Between the organizational learning strategy and the performance of human resources in the universities in question. There is a relationship of statistical significance at a moral level 0.05 . There are statistically significant differences at a moral level 0.05, Among the respondents of the study sample refers to both the variable of sex and function, in the impact of human resources development on the performance of individuals in universities. Between the training strategy, organizational learning, development (organizational, management and career development) and career creativity, and that there are no statistically significant differences at the moral level 0.05, On the impact of the human resources development strategy on the performance of individuals in universities belongs to the gender variable, functional, and that there is a strong correlation with statistical significance at the moral level 0.05, Between the training strategy and the performance of human resources in universities, and that there is a strong correlation with statistical significance at a moral level 0.05, Between the organizational learning strategy and the performance of human resources in universities, and that there is a strong correlation with statistical significance at a moral level 0.05 , Between the development strategy and the performance of human resources in the University, and that there is a strong correlation with statistical significance at a moral level 0.05 . The study noted the need for the university to research and focus on the extent to which trainees benefit from training programs.
\end{abstract}

Keywords: Development - Human Development - Human Resources Development - Performance Improving Performance.

\section{Introduction}

The modern orientation of contemporary institutions has become an emphasis on the need to pay attention to the human response, as confirmed by the literature of the development of administrative thought, the human resource in the context of an economy governed by knowledge and a world driven by rapidly rapid developments, which is not without human resources with competencies, skills and knowledge that enable them

* This article was submitted in November 2020, and accepted for publishing in January 2021.

(C) Arab Administrative Development Organization- League of Arab States, 2023, pp 227-238، DOI: 10.21608/aja.2021.81140.1108 
to continue well and effectively for the rest of the foundation's resources, and given the important role and The vital role played by the University, whose products are summarized in the development and advancement of Maat, and as the first organizations tasked with the task of generating and disseminating knowledge, it was obliged to value its human resources and raise the skills of its machines, efficiency and knowledge, through its adoption and application to the idea of investing in its human resources.( Demidova, N., Akilina, O., Kirzhetska, M., Lagovskyi, V., \& Besarab, S. 2019, 4).

Since excellence in performance is the guarantor of survival, excellence and advancement, the endeavor of each institution has become to obtain efficient human resources capable of achieving its objectives. In an equation between the university and other institutions to achieve this depends on the human competencies provided by the university to the labor market, reflecting the level and efficiency of its qualifications from professors and even administrators and at the same time reflecting excellence in university performance, and therefore the highest goal that universities seek to achieve from the development of their human resources, is to improve the performance of the university and upgrade its levels and depend mainly on the level of The performance of the human resource in it, especially in the light of the changing and dynamic environment that it lives, which forces it to keep up with developments and try to adapt and the latest developments, because it is a knowledge system that is a reflection of the social and economic issues of societies (Rubin, H. 2009), so the study deals with the development of human resources and its impact on the performance of individuals in universities and the study was applied to King Abdelaziz University in Saudi Arabia.

\section{Previous Studies:}

The impact of the strategic management of human resources and the development of competencies on the competitive advantage of the economic institution - the entrance to quality and the luxury-a thesis in management, faculty of economics and management sciences, University of Algiers,2003-2004, in which the following problem was raised: Can the strategic management of human resources through the management and development of competencies, the management of knowledge and the management of quality, affect the quality of the quality, The competitive advantage of the economic institution? Where it reaches a number of results, the most important of which is: the most important endeavor of economic institutions in the context of a strategic orientation and in the context of their possession of individual and collective human resources and competencies is to possess and maintain the competitive advantage, this depends on the application of modern management to help the development of human competencies, especially individual ones, especially the management of comprehensive quality, which is a method of improving and improving the performance of human resources within the direction of his strategy and consideration as an asset and partner in the strategies of the institution.

Hussein: Human Resources Development Strategy in the Economic Institution - The Case of the Sonagraph Foundation, a doctoral thesis in economic sciences specializing in management, in which the following problem was raised: What are the effective strategies for the development of human resources in the economic institution under the new changes? Unless organizations are willing to respond to these changes by following strategies that keep pace with the requirements of change and development, the most important of which is the development of their human resources, they are doomed to disappear.

Ben Aishi Ammar. Training programs and their role in achieving the overall quality of organizations: case study of the electric cable industry institution, $\mathrm{PhD}$ thesis in management sciences, in which the following problem was raised: how to achieve the overall quality of the organizations through the management of training programs? It has a role in achieving overall quality, that the implementation of training programs helps to achieve overall quality, that the evaluation of training programs is important in achieving overall quality, as the study confirmed a statistically significant relationship between the design of training 
programs, the identification of training needs, the evaluation of training programs and the achievement of quality in the institution in question, as it turns out that there are no statistically significant differences at the level of 0 indicative. 05 Among the respondents' answers are the variables of gender, age, job class, educational level, length of service for the five axes of the form on the role of training programs in achieving the overall quality of the institution in question.

\section{Theoretical Concepts of the Study:}

\section{The concept of human resources management:}

It is the group of individuals involved in the design of the goals, policies, activities and completion of the work carried out by the founders T (Hassan, 2002,18) and is "these groups of individuals who are able to perform the work and who wish to perform in a broad and committed manner, where the ability must be integrated and interact with the desire in a harmonious framework and increase the opportunity to effectively utilize these resources when systems are designed and developed by education, selection, training, evaluation, development and maintenance (Abu Al-Nasr, Al-Nasr) and maintenance. 2007, 31), which is "all the people who work in the institution presidents and subordinates, who have been employed in it to perform all its functions and functions under the umbrella of: its organizational culture that clarifies, controls and unifies their behavioral patterns and a set of plans, regulations, policies and procedures that regulate the performance of their tasks and the implementation of the functions of the institution, in order to achieve its mission and the objectives of its future strategy. Omar Aqili, 2005, 11, is "a group of activities that allow the organization to provide human resources that are in line with needs of interest in terms of quantity and type" (Loic. Cadin et autres, 2007: 5).

The concept of strategic human resources management in contemporary institutions is the most important product of the challenges and transformations that the world is witnessing today, from globalization, technological developments and the intensification of competition that have become global, forcing the institution to look at its human resources as a strategic resource. (Yohna Strong, 2008: 124)

It is the human resources decision-making process, which works to adapt the human resources system to the surrounding conditions and to strengthen the enterprise's strategies and achieve its strategic objectives, it is an entry or a framework for strategic decision-making on the employees of the organization at all organizational levels, where this strategic management is directed under the umbrella of the general strategy of the institution" and is concerned with formulating human resources strategies and policies, in accordance with environmental opportunities, business strategies and organizational structure;

This objectively planned and well-informed integrated process aimed at creating a workforce commensurate with the requirements of working in specific organizations, understanding the conditions, rules, methods and methods of performance required, capable of applying those rules and methods and wishing to do business using their capabilities and skills." It is "a planned work consisting of a set of programs designed to teach human resources and provide them with new knowledge, behaviors and skills in the future, thus adapting and living with any new developments in the environment that affect the activity of the institution."

The concept of performance among many researchers has been associated with the human resource alone, as it is the basis for building any institution and the active member in moving the rest of its resources. It is "the degree of achievement and completion of the tasks that make up the individual's job and reflects how an individual achieves or satisfies the requirements of the job." Itis the result of a series of activities related to a job, department or department, performed byan employee or manager to achieve a specific goal." The level achieved by the working person in the performance of his work, in terms of the quantity and quality of work provided by him". 


\section{Study Problem}

Through previous submissions and in theoretical literature and the results of previous studies, the problem of study can be identified and formulated in the following question: What is the impact of human resources development on the performance of individuals in universities?

\section{The Objectives of the Study}

1- Emphasizing the importance of human resources and the need for strategic direction in their development in universities, as one of the main pillars to achieve excellence.

2- Ranking of human resources development strategies in universities.

3- Emphasizing the need for the university to use modern management methods in the development of its human resources.

4- Re-engineering the university human performance and the measured ness of the human resources performance.

5- To reveal the reality of human resources development in universities and the strategies adopted in them.

6- Identify strategies that can raise the level of performance at the university.

\section{Study Hypotheses:}

1- There is a relationship of statistical significance at a moral level 0.05 Between the training strategy and the performance of human resources in the universities in question.

2- There is a relationship of statistical significance at a moral level 0.05 Between the organizational learning strategy and the performance of human resources in the universities in question.

3- There is a relationship of statistical significance at a moral level 0.05 Between the development strategy and the performance of human resources in universities.

4- There is a relationship of statistical significance at a moral level 0.05 Between career innovation strategy and human resources performance in universities.

5- There are statistically significant differences at a moral level of 0.05 Among the respondents of the study sample refers to both the gender variable, the function, the impact of human resources development on the performance of individuals in universities.

\section{Study Methodology:}

- Type of study. Descriptive study.

- Curriculum: Descriptive analytical approach.

- Study community. The study community is made up of 39 employees of King Abdelaziz University in Saudi Arabia.

- Study tool (data collection tool): A questionnaire consisting of the raw data part and the dimension supplant and contained 42 words.

\section{The constructive honesty of the study tool (questionnaire):}

We note from the table (1) that the coefficients of correlation of each axis with the overall degree of the scale (all the paragraphs of the ques-
Table 1- The coefficients of the axis's correlation with each other and the overall scale of the scale

\begin{tabular}{cc}
\hline Axes & $\begin{array}{c}\text { Total degree of } \\
\text { questionnaire }\end{array}$ \\
\hline The first axis & $.956^{* *}$ \\
\hline Axis 2 & $.977^{* *}$ \\
\hline Axis 3 & $.980^{* *}$ \\
\hline Axis 4 & $.964^{* *}$ \\
\hline Axis 5 & $.664^{* *}$ \\
\hline
\end{tabular}

** Correlation is significant at the 0.01 level (2-tailed). 
tionnaire), that all the correlation coefficients shown in the table are limited between the two values ( 0.664 - 0.980) it is a function at a moral level (0.05), This reflects the constructive honesty of the study tool.

\section{Stability of the study tool (questionnaire):}

From the table (2), the alpha stability factor for the surveys of the questionnaire is valued at $0.797-0.949)$, and the total stability factor (0.978)These values are very high, which means that the stability factor of the axes is high, which confirms that the instrument (questionnaire) has a high and appropriate degree of stability and measures what has been developed to measure it, so it is up to the purposes of the study.

\section{Study Results:}

Table 2 - Values of the Alpha Ker N Bach

(Cronbach's Alpha)

\begin{tabular}{clc}
\hline Axis No. & \multicolumn{1}{c}{ Axis address } & Stability factor \\
\hline 1 & $\begin{array}{l}\text { Training is a human resources develop- } \\
\text { ment strategy at the university }\end{array}$ & 0.894 \\
\hline 2 & $\begin{array}{l}\text { Organizational learning strategy for human } \\
\text { resources development at the university }\end{array}$ & 0.949 \\
\hline 3 & $\begin{array}{l}\text { Development strategy for human resourc- } \\
\text { es development at the university }\end{array}$ & 0.932 \\
\hline 4 & $\begin{array}{l}\text { Creativity is a strategy for the develop- } \\
\text { ment of human resources at the university }\end{array}$ & 0.873 \\
\hline 5 & $\begin{array}{l}\text { The level of human resources performance } \\
\text { at the university }\end{array}$ & 0.797 \\
\hline & All the axes of the questionnaire & 0.978 \\
\hline
\end{tabular}

\section{Test in hypotheses of the study:}

Q1. There is a relationship of statistical significance at a moral level 0.05 Between the training strategy and the performance of human resources in the universities in question:

It is clear from the table (3) that the value of the correlation coefficient between the training strategy and the performance of human resources at the university is 0.671 and a moral level. which is less than 0.05 Which means that there is a statistically significant cosplay correlation at a moral level of 0.05 Between

Table 3 - Relationship between the training strategy and the performance of human resources at the university

\begin{tabular}{ccc} 
& & $\begin{array}{c}\text { University Training } \\
\text { Strategy }\end{array}$ \\
\hline Human & Pearson Correlation Coefficient & $.671^{* *}$ \\
\cline { 2 - 3 } resources & Moral level & 0.000 \\
\cline { 2 - 3 } performance & Number of individuals & 39 \\
\hline
\end{tabular}

**. Correlation is significant at the 0.01 level (2-tailed). the training strategy of the universities under study as an independent variable and the performance of human resources in them as a dependent variable, which is a Medium correlation, this means the realization of the first hypothesis.

\section{Q2. There is a relationship of statistical significance at a moral level 0.05 Between the organizational learning strategy and the performance of human resources in the universities in question:}

It is clear from the table (4) that the value of the correlation coefficient between the organizational learning strategy and the performance of human resources at the university is 0.637 and a moral level 0.001 which is less than 0.05 Which means that there is a statistically significant cosplay correlation at a moral level of 0.05 Between the organizational learning strategy of the universities under study as an independent variable and the performance of

Table 4 - Relationship between organizational learning strategy and human resources performance at the university

\begin{tabular}{ccc}
\hline \multirow{2}{*}{$\begin{array}{c}\text { Human } \\
\text { resources } \\
\text { performance }\end{array}$} & Pearson Correlation Coefficient & $\begin{array}{c}\text { University Organizational } \\
\text { Learning Strategy }\end{array}$ \\
\cline { 2 - 3 } & Noral level & $.637^{* *}$ \\
\cline { 2 - 3 } & Number of individuals & 0.000 \\
\hline
\end{tabular}

**. Correlation is significant at the 0.01 level (2-tailed). 
human resources in them as a dependent variable, which is a strong correlation, this means the realization of the second hypothesis.

\section{Q3. There is a relationship of statistical significance at a moral level 0.05 Between the development strategy and the performance of human resources in universities:}

From the table (5) itis shown that the value of the correlation coefficient between the development strategy and the performance of human resources in the university is equal to 0.661 and a moral level 0.001 which is less than 0.05 Which means that there is a statistically significant cosplay correlation at a moral level of 0.05 Between the development strategy of the universities under study as an independent variable and the performance of human resources in them as a dependent variable, which is a strong correlation, this means the realization of the third hypothesis.

\section{Q4. There is a relationship of statistical significance at a moral level 0.05 Between career innovation strategy and human resources performance in universities.}

The table (6) shows that the value of the correlation coefficient between the strategy of career innovation and the performance of human resources at the university is equal to 0.594 and a moral level. 0.001 which is less than 0.05 Which means that there is a statistically significant cosplay correlation at a moral level of 0.05 Between the strategy of career innovation in the universities studied as an independent variable and the performance of human resources in them as a dependent variable, which is a strong correlation, thus achieving the fourth hypothesis.
Table 5 - Relationship between the development strategy and the performance of human resources at the university

\begin{tabular}{ccc}
\hline Pearson Correlation Coefficient & $\begin{array}{c}\text { University Development } \\
\text { Strategy }\end{array}$ \\
\hline \multirow{2}{*}{$\begin{array}{c}\text { Human } \\
\text { resources } \\
\text { performance }\end{array}$} & $\begin{array}{c}\text { Pearson Correlation } \\
\text { Coefficient }\end{array}$ & $0.661^{* *}$ \\
\cline { 2 - 3 } & Moral level & 0.000 \\
\cline { 2 - 3 } & Number of individuals & 39 \\
\hline
\end{tabular}

**. Correlation is significant at the 0.01 level (2-tailed).

\section{Q5. There are statistically significant differences at a moral level of 0.05 Among the respondents of} the study sample refers to both the gender variable, the job, the impact of human resources development on the performance of individuals in universities.

This hypothesis is branched out by the following sub hypotheses:

The first sub hypothesis: There are no statistically significant differences at a moral level 0.05 Among the respondents of the study sample refers to the gender variable, for the five axes of the form on the impact of the HUMAN Resources Development Strategy on the performance of individuals in universities.

The table (7) shows that the $t$ value of each axis is at a degree of freedom of 37 and a level of 0.05 equals 0.308 which is less than the $\mathrm{t}$-scale value of 1.96 As well as the value of the moral level reached 0.760 which is greater than 0.05 Which means accepting the nihilistic hypothesis $\mathrm{H} 0$, which says that there are no statistically significant differences at a moral level 0.05 On the impact of strategy on the performance of individuals in the universities in question belongs to the sex variable (male, female) 
Table 7-Showing T test for independent samples belonging to the sex variable (Independent Samples T Test

\begin{tabular}{|c|c|c|c|c|}
\hline \multirow{2}{*}{ Axes } & \multicolumn{2}{|c|}{ Average arithmetic } & \multirow{2}{*}{ T value } & \multirow{2}{*}{$\begin{array}{l}\text { Mora } \\
\text { level }\end{array}$} \\
\hline & male & Female & & \\
\hline Training is a human resources development strategy at the university & 2.32 & 2.31 & 0.068 & 0.946 \\
\hline Organizational learning strategy for human resources development at the university & 2.25 & 2.18 & 0.287 & 0.776 \\
\hline Development strategy for human resources development at the university & 2.33 & 2.20 & 0.593 & 0.556 \\
\hline Creativity is a strategy for the development of human resources at the university & 2.15 & 2.11 & 0.184 & 0.855 \\
\hline The level of human resources performance at the university & 2.67 & 2.82 & -1.161 & 0.253 \\
\hline All axes & 2.28 & 2.21 & 0.308 & 0.760 \\
\hline
\end{tabular}

Sub-hypothesis: There are no statistically significant differences at a moral level 0.05 Among the respondents of the study sample refers to the variable of the function, for the five axes of the form on the impact of the Human Resources Development Strategy on the performance of individuals in the universities in question.

Table 8 - T test number table for independent samples returns to job changer (Independent Samples T Test)

\begin{tabular}{|c|c|c|c|c|}
\hline \multirow{2}{*}{ Axes } & \multicolumn{2}{|c|}{ Average arithmetic } & \multirow{2}{*}{$\begin{array}{c}\mathrm{T} \\
\text { value }\end{array}$} & \multirow{2}{*}{$\begin{array}{l}\text { Moral } \\
\text { level }\end{array}$} \\
\hline & Officer & Faculty & & \\
\hline Training is a human resources development strategy at the university & 2.19 & 2.47 & 1.74 & 0.09 \\
\hline Organizational learning strategy for human resources development at the university & 2.10 & 2.32 & 1.08 & 0.29 \\
\hline Development strategy for human resources development at the university & 2.15 & 2.35 & 1.12 & 0.27 \\
\hline Creativity is a strategy for the development of human resources at the university & 2.03 & 2.23 & 1.05 & 0.30 \\
\hline The level of human resources performance at the university & 2.77 & 2.79 & 0.11 & 0.91 \\
\hline All axes & 2.13 & 2.36 & 1.28 & 0.21 \\
\hline
\end{tabular}

The table shows that the $t$ value of each axis is at a degree of freedom of 37 and a level of 0.05 is equal to 1.28 which is less than the t-scale value of 1.96 As well as the value of the moral level was 0.086 which is greater than 0.05 Which means accepting the nihilistic hypothesis $\mathrm{H} 0$, which says that there are no statistically significant differences at a moral level 0.05 On the impact of development strategy on the performance of individuals in the universities in question belongs to the job changer (faculty, administrative officer).

\section{Discuss the Results of the Study Hypotheses test:}

\section{Discuss the results of the first hypothesis test:}

The data obtained from the analysis of the results of the first hypothesis, using the Pearson Correlation Coefficient to determine the relationship between the study variables (the training strategy as an independent variable and the performance of human resources in the university as a dependent variable), showed a positive, strong and statistically significant correlation relationship with a correlation factor equal 0.671 at the 0.05 -indicative level. This is in line with the theoretical framework of the study of the importance of the training strategy as one of the strategies for human resources development in raising and improving the performance of human resources at the university, this confirms the realization of the first hypothesis.

\section{Discuss the results of the second hypothesis test:}

The data obtained from the analysis of the results of the second hypothesis, using the Pearson Correlation Coefficient to determine the relationship between the study variables (the organizational learning strategy as an independent variable and the performance of human resources in the university as a dependent 
variable), showed a positive, strong and statistically significant correlation with a correlation factor equal to 0.637 at the 0.05 -indicative level. This is in keeping with the theoretical framework of the study of the importance of the organizational learning strategy as one of the strategies of human resources development in raising and improving the performance of human resources at the university, this confirms the realization of the second hypothesis.

\section{Discuss the Results of the Third Hypothesis Test:}

The data obtained from the analysis of the results of the third hypothesis, using the Pearson Correlation Coefficient to determine the relationship between the study variables (development strategy as an independent variable and the performance of human resources in the university as a dependent variable), showed a positive, strong and statistically significant correlation relationship with a correlation factor equal 0.661 at the 0.05 -indicative level. This is in line with the theoretical framework of the study of the importance of the development strategy as one of the human resources development strategies in raising and improving the performance of human resources at the university.

\section{Discuss the Results of the Fourth Hypothesis Test:}

The data obtained from the analysis of the results of the fourth hypothesis, using the Pearson Correlation Coefficient to determine the relationship between the study variables (functional innovation strategy as an independent variable and the performance of human resources in the university as a dependent variable), showed a positive, strong and statistically significant correlation relationship with a correlation coefficient equal to 0.594 at the 0.05 -indicative level. This is in line with the theoretical framework of the study of the importance of the strategy of functional creativity as one of the strategies for the development of human resources in raising and improving the performance of the human resources at the university, this confirms the realization of the fourth hypothesis.

\section{Discuss the Results of the Fifth Hypothesis Test:}

Using the Independent Samples T Test in the first and second sub-hypothesis to detect the presence or absence of statistically significant differences due to the gender and function variable on the impact of strategy on the performance of individuals in universities:

The data obtained from the analysis of the results of the first sub hypothesis, using the Independent Samples T Test, showed that there were or no statistically significant differences at a moral level of 0.05 On the impact of development strategy on the performance of individuals in the universities in question belongs to the sex variable (male, female), where it showed no statistically significant differences at a moral level 0.05 On the impact of dying strategy on the performance of individuals in the universities in question belongs to the sex variable (male, female), this confirms the realization of the first sub hypothesis.

The data obtained from the analysis of the results of the second sub hypothesis, using the Independent Samples T Test, showed that there were or no statistically significant differences at a moral level of 0.05 On the impact of the human resources development strategy on the performance of individuals in the universities in question belongs to the change of position (professor, administrative officer). 0.05 On the impact of strategy on the performance of individuals in universities belongs to the job changer (professor and administrative officer), this confirms the realization of the second sub-hypothesis. 


\section{Overall Results:}

- The University adopts the training strategy in raising the skills, expertise and knowledge of its employees, professors and administrative staff, and the training is a strong motivation for employees to raise their performance levels by providing them with skills and qualifications to help do so, as well as to bring the culture of employees closer to the culture of the university and create common visions and objectives among them, this will raise the spirit of belonging generated mainly by the satisfaction of employees and their performance levels,

- The study confirmed the existence of some flaws in the practices of this training strategy, the most important of which was that the university does not compare the performance of the trainee staff before and after the training process and evaluate it to determine the effectiveness of the training programs, which means the absence of the study of feedback.

- The University adopts an organizational learning strategy, focusing the contents of organizational learning programs to stem from the reality of job requirements and to satisfy and cover them, helping the employee to raise and improve his or her career levels and make it more efficient and effective.

- The objectives of organizational learning are to build learning programs focused on the quality of skills, expertise and knowledge acquired by employees in the exercise of this strategy, among the most important of these skills: communication and communication skills that open the door to the exchange of experiences and information.

- The University adopts the development strategy of organizational development, management and career development in the development of its human resources, through which it works to refine and value their knowledge.

- The University adopts career innovation as an important strategy for the development of its human resources, through which it works to instill and develop creative culture among its employees, raising the skills of creative thinking and logical analysis of its employees.

- The performance levels of the university's professors and administrative staff are above-accepted.

- There is a relationship of statistical significance at a moral level 0.05 between training strategy, organizational learning, development (organizational, management and career development) and career creativity.

- There are no statistically significant differences at a moral level 0.05 On the impact of the HR Strategy on the performance of individuals in universities is due to the gender variable, career, age, scientific qualification and career experience.

- Universities are among the organizations that are working to develop their intellectual capital as an urgent necessity to raise their different levels within their various roles.

- The success of the university's human resources development strategy depends on its adoption of new models in its design, based mainly on the philosophy of continuous learning, helping to keep pace with changes in the external environment.

- The success of the human resources training strategy at the university depends on building its programs from the realities of their training needs and from the point of view of changing the style of performance and behavior and thinking for the better.

- Organizational learning is the cornerstone of building an educated university, so that its values, structures, management systems and organizational culture must be encouraged by learning in their human resources, thereby increasing their knowledge, skills and experience. 
- The organizational development of the university aims to improve the skills and efficiency of the human resources, and this leads to the increase of the efficiency of the university and then improve its performance, this requires the mobilization of technical, material and environmental resources to make the human resources development strategy a success.

- As part of its adoption of the management development strategy, the University provides its staff with the right knowledge and skills, interaction skills, communication and convergence of views, so that they participate in achieving the university's goals.

- The career development strategy enables human resources at the university to possess a skill base, knowledge and experience, enabling them to face career change and thus rise to higher positions, thus ensuring that the University has the qualified human resources and skills and expertise that are cadres ready to face any change.

- Career creativity is an important strategy that inspires the movement and development of the knowledge components of the university's human resource, unlocking its creative energies, career talents and constantly developing it, in addition to providing it with creative thinking skills in problem-solving.

- The results of the Human Performance Assessment are the starting point and the university's first reference in making many decisions related to its human resources issues, including: career enrichment, human resources development, the establishment of a fair incentive system, etc.; 360 Evaluation (Degree Evaluation-360),modern and important entries in evaluating the performance of the human response can be adopted by the University due to its comprehensiveness that gives it accuracy in the results and credibility in identifying the existing performance gap expressed by the estimated and achieved performance.

- The University's human resources development strategies raise and improve staff performance by raising their career skills and enriching their professional knowledge and experience.

- The university under study is aware of the importance of the training strategy in raising the skills, expertise and knowledge of its human resources of professors and administrative staff, but the study confirmed the existence of some imbalances in the practices of this strategy, which somewhat reduced its effectiveness.

- The University is aware of the importance of an organizational learning strategy in enhancing staff skills and raising their knowledge and experience.

- Organizational and administrative development and career development are important strategies to increase the functional capacity of human resources in universities.

- Career innovation is an important strategy for the development of human resources in universities.

- There is a strong correlation with statistical significance at a moral level 0.05 Between the training strategy and the performance of human resources in universities.

- There is a strong correlation with statistical significance at a moral level 0.05 Between the organizational learning strategy and the performance of human resources in universities.

- There is a strong correlation with statistical significance at a moral level 0.05 Between the development strategy and the performance of human resources in the University.

- There is a strong correlation with statistical significance at a moral level 0.05 Between the strategy of career innovation and the performance of human resources in universities.

- There are no statistically significant differences at a moral level 0.05 On the impact of the HUMAN Resources Development Strategy on the performance of individuals in universities is due to the sex variable. 
- There are no statistically significant differences at a moral level 0.05 On the impact of the human resources development strategy on the performance of individuals in universities is due to a career change.

- There are no statistically significant differences at a moral level 0.05 On the impact of the human resources development strategy on the performance of individuals in universities is due to the change of age.

- There are no statistically significant differences at a moral level 0.05 On the impact of the human resources development strategy on the performance of individuals in universities is due to the change of scientific qualification.

- There are no statistically significant differences at a moral level 0.05 On the impact of the HR Strategy on the performance of individuals in universities is due to a change in career experience.

\section{Study Recommendations:}

- The need for the university to research and focus in the collection of feedback on the extent to which trainees benefit from training programs.

- The need to pay attention to the evaluation of staff performance, as it is the way to identify the performance gap and disclose actual training needs.

- The need to adopt the idea of discussing business mistakes and applying performance improvement strategies.

- The need to develop the university's awareness of the importance of broad diversification in psychological tools (physical and moral stimulation).

- Re-engineering human resources and their role in supporting the human resources development strategy.

- To update the university's role in light of current challenges and knowledge management requirements. 


\section{References:}

- $\quad$ A lot, Hassan. (2002). Strategic Ally. Arab Renaissance House, Beirut.

- $\quad$ Abu Al-Nasr, Medhat Mohammed. (2007). Human Resources Management and Development: Contemporary Trends. Nile Arab Group, Cairo.

- $\quad$ Al-Malakaoui, Ibrahim. (2009). Performance Management Using Balanced Scorecard. Al-Warraq Publishing and Distribution, Amman.

- Al-Sheikh, Al-Dawi.(2010). "Analysis of the Theoretical Foundations of the Concept of Performance", Researcher's Journal, University of Qasdi Marbah and Reqala, Issue (07).

- Ammar, Ben Aishi. (2013). "Training programs and their role in achieving the overall quality of organizations: case study of the electric cable industry institution - Biskra", Doctor of Science in Management Sciences, Faculty of Economic and Commercial Sciences and Management Sciences, Department of Management Sciences, Biskra University.

- Aqili, Omar Wasfi. (2005). Contemporary Human Resources Department: Strategic Dimension. Wael Publishing and Distribution House, Amman.

- Bartoli, Annie. (2015). Le Management Dans les Organizations Pulques. Edition Dunned, Paris.

- Cadin, Loic et autres. (2007). Gestion Des Ressources Humaines: Pratiques et Eléments de Théorie.

- Demidova, N.; Akilina, O.; Kirzhetska, M.; Lagovskyi, V. \& Besarab, S. (2019). “Accumulation and Fulfilment of the Human Capital Potential in Order to Strengthen the Economic Security1", Journal of Security \& Sustainability, Issues, 8 (4).

- Hamdaoui, Wassila. (2004). Human Resources Department, Publishing Directorate, Qalam University, Algeria.

- $\quad$ Mohammed, Rawia. (2004). Human Resources Department, Vision for the Future - University House, Alexandria.

- Mougin, Yvon. (1996). Processus: Les Outils D'optimisation De La Performance. Editions EyE rolles.

- Qawiun, Bohania. (2008). Human Resources Development in the Light of Globalization and the Information Society, Academic Book Center, Amman, 2008.

- Rubin, H. (2009). Collaborative Leadership: Developing Effective Partnerships for Communities and Schools. Corwin Press.

- Sabarina, Manie .(2015). "The Impact of the Strategic Management of Human Resources and the Development of Competencies on the Competitive Advantage of the Economic Foundation", Doctoral Thesis in Economic Sciences, University of Algiers.

- Yarqi, Hossein. (2008). "Human Resources Development Strategy", Sonagraph Foundation, Published Doctoral Thesis, University of Algiers. 